19 Revue d'histoire du XIXe siècle

Société d'histoire de la révolution de 1848 et des

révolutions du XIXe siècle

$37 \mid 2008$

L'ère victorienne revisitée

François PARDIGON, Épisodes des journées de juin 1848 Jean-Claude Caron

OpenEdition

Journals

Édition électronique

URL : http://journals.openedition.org/rh19/3530

DOI : $10.4000 /$ rh 19.3530

ISSN : $1777-5329$

Éditeur

La Société de 1848

Édition imprimée

Date de publication : 15 novembre 2008

Pagination : 185-242

ISSN : 1265-1354

Référence électronique

Jean-Claude Caron, «François PARDIGON, Épisodes des journées de juin 1848 », Revue d'histoire du XIXe siècle [En ligne], 37 | 2008, mis en ligne le 01 décembre 2008, consulté le 22 septembre 2020. URL

http://journals.openedition.org/rh19/3530 ; DOI : https://doi.org/10.4000/rh19.3530

Ce document a été généré automatiquement le 22 septembre 2020.

Tous droits réservés 


\title{
François PARDIGON, Épisodes des journées de juin 1848
}

\author{
Jean-Claude Caron
}

\section{RÉFÉRENCE}

François PARDIGON, Épisodes des journées de juin 1848, présentation d'Alix Héricord, Paris, La Fabrique éditions, 2008, 289 p. ISBN : 978-2-913372-78-8. 17 euros.

1 Après avoir réédité le Prologue d'une révolution de Louis Ménard, il y avait une logique certaine à rééditer François Pardigon. Non que le propos ou l'ambition soient identiques. Car si les deux ouvrages « ramènent la politique à ce qu'elle ne cesse jamais d'être tout à fait : une guerre », pour reprendre la formule d'Alix Héricord appliquée au témoignage de François Pardigon, ce dernier n'a pas le même point de vue que Louis Ménard, au sens topographique comme narratif. Arrêté dès le 23 juin, François Pardigon n'est pas un témoin de l'événement-juin 1848 - au sens de combat, de lutte -, mais de la répression des vaincus par les vainqueurs. Ce n'est pas la barricade qui est au cœur du récit, publié dès avril-mai 1849 dans La Vraie République, mais la prison dans ce qu'elle a de plus inhumain. Les dix séquences qui composent la démonstration, après une roborative introduction, sont devenues un volume publié en 1852 depuis l'exil. Livre de proscrit, les Épisodes ne sont pas une œuvre historique ; ils n'ont pas non plus l'ampleur investigatrice de l'ouvrage de Louis Ménard. Le récit est construit autour des dix "stations du chemin de croix du narrateur» (Alix Héricord), devenu de ce fait l'objet central d'une sorte d'autobiographie du martyr de la révolution. La litanie des casernes (des Grès, de Tournon), des prisons (de l'Abbaye), des caveaux (des Tuileries), des palais transformés en lieux de détention (Palais-Royal), des hôpitaux (La Charité) remplit l'ouvrage des différentes facettes de l'esprit humain en temps de guerre civile. Et, en point d'orgue, surgit l'épisode du transfert des prisonniers entassés dans les souterrains des Tuileries qui se termine par le massacre de la place du Carrousel, sur lequel François Pardigon livre l'unique témoignage de ceux qui en furent les victimes. 
2 Pour autant, les Épisodes ne sont pas un livre de la plainte et de la douleur, mais un ouvrage militant, gardant foi dans l'inéluctabilité de la prochaine et vraie révolution. François Pardigon pose, non le premier, mais avec force, la question révélée avec acuité par juin 1848 de la nature de la citoyenneté et de sa traduction sacralisée, le vote universel. «Le premier acheminement, et le plus facile, vers la sincérité du vote universel, est l'armement universel». On voit ce qu'une telle phrase, nourrie de l'expérience de juin 1848 mais tout autant de décembre 1851, introduit dans le débat sur les notions de citoyenneté, de république et de démocratie. Nul besoin, par ailleurs, de forcer le trait et de tenter d'inscrire François Pardigon dans une "constellation historiographique blanquiste ». Modeste par ses origines, le jeune Provençal, né à Salon-de-Provence en 1826, s'inscrit dans une stratégie à la fois banale et exemplaire d'ascension sociale par l'apprentissage du droit à Paris (et non à Aix) sous la monarchie de Juillet. Les quelques relations familiales et "compatriotiques" lui serviront à échapper au pire - les pontons -, témoignant ainsi d'une forme de solidarité sociale maintenue y compris dans le règlement de la guerre civile. Cela ne lui suffit pas, pour autant, à éviter le chemin de la proscription au lendemain du 13 juin 1849, à Londres, puis, dix ans plus tard, et avant que l'amnistie ne soit accordée par Napoléon III, aux États-Unis. Là il vécut d'enseignement et de journalisme en Virginie et, lors de la guerre de Sécession, s'engagea du côté des Sudistes... « En l'état actuel des connaissances, on ne peut guère dire comment Pardigon comprit ce à quoi il participait » : l'affirmation apparaît pour le moins discutable, pour un homme dont le passé politique témoigne d'une vraie familiarité avec la politique et qui sait ce que choisir son camp veut dire.

3 François Pardigon a du style : hugolien parfois, dans la vigueur de la formule qui claque comme une vérité absolue, il sait construire un récit où alternent le témoignage personnel, incluant l'usage du «je ", l'histoire vue à ras du sol et le propos en surplomb, inscrivant l'événement dans la quête de justice sociale menée par l'humanité. L'œil distingue en particulier la nature des combattants : hommes, femmes, enfants. Dans la mesure du possible, François Pardigon tente d'échapper à une reconstruction de l'insurrection et donne l'impression d'écrire un récit dans le déroulement même de l'action à laquelle il participe, sans connaître l'ensemble des scènes de l'événement. C'est là que son récit apporte le plus. En particulier dans les formes avortées de négociation qui s'ébauchent en vain, dans les tentatives de conciliation qui échouent, dans la progressive radicalisation des camps et l'impossible neutralité qui se dessine. Du fait de la précocité de son arrestation, François Pardigon en est réduit à décrire le monde des prisonniers et des mauvais traitements qu'ils subissent; mais il élève aussi le débat à une réflexion sur l'inhumanité qui émane parfois de ses compagnons d'infortune, soucieux de sauver leur peau. La distance sociale, culturelle, sociologique demeure entre des individus qui ont fait le même choix, mais pas nécessairement pour les mêmes raisons. L'argent même peut améliorer le sort de certains. Les deux chapitres consacrés au caveau des Tuileries et à la fusillade de la place du Carrousel décrivent l'acmé de la déshumanisation des prisonniers par leurs gardiens, malgré des élans d'humanité individuels.

Dans l'appendice de son récit, François Pardigon compare juin 1848 et juin 1849 et entend donner une dimension européenne, voire internationale à ce combat pour la "sociale ». Son propos ne vise pas à théoriser la chose. Comme Louis Ménard, il participe à la mythologisation du "peuple », mais le niveau de l'analyse reste du domaine des stéréotypes. L'appel à la «guerre aux rois» résonne bizarrement dans 
cette conclusion portée par l'actualité romaine du printemps 1849. «Quand le drapeau rouge sera arboré, il ne lui sera point reproché d'avoir marché contre des frères en république, car il s'est levé contre le drapeau tricolore, et, pur de toute tache, pour l'affranchissement universel, il pourra faire le tour du monde ", écrit Pardigon en référence et en réponse (tardive) à la fameuse formule lancée par Lamartine le 25 février 1848. Le tour du monde de François Pardigon l'entraîna, on l'a vu, en Angleterre, puis aux États-Unis. Après une dernière preuve de vie enregistrée en 1875, sa trace se perd. Il aurait été intéressant de connaître les sentiments du combattant d'Appomattox - dans les rangs sudistes - envers cette Troisième République qui vit le triomphe des principes de février plus que de juin 1848. 